\title{
"Para que el winka sepa que este territorio lo llamamos de otra forma" Producción de memorias y experiencias de territorio entre los mapuche de Norpatagonia
}

\section{Ana Ramos}

IIDyPCa/CONICET/UNRN, San Carlos de Bariloche, Argentina.

Correo electrónico: aramosam@gmail.com

Doctora en Antropología y docente Universidad Nacional de Río Negro

\section{Lorena Cañuqueo}

Universidad Nacional de Río Negro, San Carlos de Bariloche, Argentina.

Correo electrónico: Icanuqueo@unrn.edu.ar

Licenciada en Comunicación Social, doctoranda en Antropología y docente Universidad Nacional de Río Negro
Recibido:

28 de julio de 2017

Aceptado:

23 de marzo de 2018

\section{Resumen}

Este trabajo aborda la relación entre memoria y territorio a partir de revisar los sentidos que adquieren las prácticas del espacio de grupos mapuche en Norpatagonia en contextos de subordinación. La necesidad de definir territorio y ocupación tradicional para aplicar una política pública permitió dimensionar la importancia de los marcos de interpretación de estos grupos sobre los quiebres y continuidades entre presente y pasado. En estos marcos, el territorio se explica a partir de restaurar nociones de "hablar bien" (una comunicación anclada en la reciprocidad entre las personas y con el entorno) y de "movimiento" (en "campos abiertos"). Siguiendo los usos locales de estas nociones, nos proponemos mostrar cómo se va produciendo una experiencia compartida en torno al territorio, tanto al "levantar las palabras antiguas", como al recordar las "andanzas" de sus antepasados.

"So the winka knows we call this territory differently": production of memories and restoration of Mapuche knowledge in Argentine North Patagonia

\section{Abstract}

This paper approaches the relation between memory and territory through the analysis of meanings attached to space practices of Mapuche groups in northern Patagonia in contexts of subordination. The meanings examined

Key words

Memory (Report); Territory; Knowledge Mapuche; Mapuzungun; Policy

\section{Palabras clave}

Memoria; Territorio; Conocimiento Mapuche; Mapuzungun; Política 
emerged during a workshop conducted within the framework of the implementation of National Law 26.160, involving indigenous territorial survey in Argentina. The need to define territory and traditional occupation in order to apply a public policy highlighted the importance of Mapuche interpretation frameworks regarding gaps and continuities between present and past. Within these frameworks, territory is explained by restoring notions about "speaking well" (a way of communication anchored in reciprocity between people and with the environment) and "movement" ("in open fields"). These notions are also defined in opposition to the practices of power based on "lies" and "imposition" that produced epistemic silence and territorial spoliation respectively.

\section{"Para o winka saber que este território podemos chamá-lo de outra forma": produção de memória e experiências de territó- rio entre os Mapuche da Norpatonia}

\section{Resumo}

Palavras-chave

Memória; Território; Conhecimento Mapuche; Mapuzungun; Políticas
1. Winka es la denominación utilizada en sentido general para nombrar a quienes "llegaron de otra parte" - esto es, que no son originarios del territorio mapuche.

En los siguientes apartados, ampliamos los sentidos que adquiere al connotar un modo de actuar contrapuesto al mapuche.
O trabalho aborda a relação entre memória e território a partir da revisão dos sentidos que adquirem as práticas espaciais dos agrupamentos Mapuche na área norte da Patagônia em contextos de subordinação. A necessidade de definir território de ocupação tradicional e implementar uma política pública permitiu medir a importância dos marcos interpretativos Mapuche em relação às rupturas e continuidades entre o presente e o passado. Nestes marcos, o território é explicado pela restauração das noções de "falar bem" (um tipo de comunicação ancorado na reciprocidade entre as pessoas e o meio ambiente) e "movimento" (em "campos abertos"). Noções que também são definidas em oposição às práticas de poder baseadas nas "mentiras" e na "imposição" que produziu, respectivamente, o silêncio epistêmico e a expropriação territorial.

¿Es posible acordar una definición de territorio que sea operativa para el Estado y que al mismo tiempo no traicione los reclamos más amplios del pueblo mapuche? ¿De qué maneras, en los trabajos colectivos de memoria, las personas mapuche organizan sus experiencias heterogéneas e históricas en torno al territorio? ¿Cuáles son los efectos políticos de estas reflexiones sobre el pasado? Estas son algunas de las preguntas que estuvieron presentes entre los funcionarios del Estado y las personas mapuche durante las negociaciones que se desarrollaron en el marco del Programa Nacional de Relevamiento Territorial de Comunidades Indígenas. Partiendo de estas preguntas, buscamos entender cuáles son "esas otras formas" de entender el territorio a las que hacen referencia las personas mapuche que participaron de esas negociaciones en la provincia de Río Negro. Específicamente, ¿qué es lo que las personas mapuche insisten en señalar que queda por fuera del entendimiento del wink ${ }^{1}$ cuando afirman que ellos llaman al territorio de otra forma?

Al conversar sobre asuntos antiguos o, lo que es lo mismo, al hacer memoria juntos, las personas mapuche suelen actualizar experiencias de mundo en las que no existe hiato o quiebre entre el universo de la gente (che) y el de los seres no humanos del entorno en el que se instancian las fuerzas (newen). La comprensión de la ausencia de estas rupturas es clave para entender también las 
relacionalidades que producen el espacio como wallmapu o territorio mapuche. Por otra parte, en estas ocasiones de recuerdo colectivo, el hiato o quiebre emerge, pero como una consecuencia histórica de las imposiciones de los procesos de colonización - referenciados como la intromisión winka en sus vidas - que dividieron la historia del pueblo mapuche en un "antes" y un "después". La ruptura ontológica con sus mundos ancestrales vino de la mano del despojo territorial y de la introducción de "las ontologías históricas del conocimiento moderno" (De la Cadena, 2015: 13) para las cuales sus concepciones de territorio y sus formas de actuar en él no solo son ajenas sino también impensables. Esta idea de quiebre, como consecuencia de las relaciones entre el pueblo mapuche y los Estados nacionales, es clave para comprender el modo en que las personas mapuche contraponen los modos de circular o de moverse en el territorio entre quienes "son-en-la-tierra" y los winka.

Frente a los constantes desalojos de las personas mapuche por parte del Estado o de privados, el reclamo territorial y la seguridad jurídica sobre los territorios defendidos, recuperados o por recuperar devinieron en una necesaria e imperiosa demanda colectiva a la Nación. Frente a estas y otras demandas, la Argentina aprobó en el año 2006 una ley nacional de emergencia para frenar los desalojos hasta culminar un relevamiento histórico de la situación catastral y jurídica en que se encuentran las distintas comunidades reconocidas oficialmente. ${ }^{2}$ Transcurridos cinco años desde el inicio del programa, en Río Negro se evidenciaron una serie de problemas en diferentes niveles de su ejecución. Entre ellos, cobró relevancia la manera en que ciertos conceptos incorporados al trabajo de relevamiento resultaron divergentes en sus supuestos acerca de cómo debía ser entendido el territorio (Guiñazú y Cohen, 2012; Cañuqueo y Tozzini, 2013; Cañuqueo, 2015), por lo que se propuso, para salvar esas dificultades, la realización de un taller, que consistió en acordar una noción de territorio que resultara operativa en términos administrativos. En el transcurso de este taller, los participantes mapuche subrayaron la dificultad del Estado para comprender tanto la ausencia de quiebres en las relacionalidades que constituyen el territorio mapuche, como la negación de los hiatos que la memoria mapuche identifica como imposiciones coloniales.

Si nos centramos en este proceso de negociación, consideramos que el acto de expresar las relaciones indígenas humanos-territorio en el lenguaje de las leyes estatales de propiedad es necesariamente una traducción cultural que provoca un sinnúmero de "equívocos" (De la Cadena, 2015: 27) con importantes consecuencias políticas. Cualquier traducción de la noción de territorio en esos términos debe ser entendida en su propio contexto colonial, en el cual el lenguaje de la propiedad orienta de modos específicos los esfuerzos por integrar a los indígenas y sus tierras más completamente en el Estado nación moderno, lo que subvierte así necesariamente las heterogéneas relaciones que pretende representar (Nadasdy, 2002: 252). Sin embargo, y en coincidencia con este autor, si las personas indígenas desean reclamar alguna forma de control sobre sus territorios y ser vistas como legítimas por otras en el contexto de los Estados nación modernos, deben embarcarse en estas tareas de traducción y decidir, sobre la marcha, cómo manejarse frente al poder que subyace en ellas.

Sin negar estos márgenes estrechos de maniobra, proponemos analizar los emprendimientos de traducción como intentos por objetivar transitoriamente ciertas "conexiones parciales" (Strathern, 2004) entre experiencias de mundo diferentes (De la Cadena, 2015). ${ }^{3}$ Las negociaciones políticas entre estos mundos parcialmente conectados pueden, en ocasiones, producir traducciones erróneas que anulan las diferencias ontológicas en pos de la sujeción y el
2. La Ley Nacional 26.160 de relevamiento territorial indígena - prorrogada en el año 2017 por otros cuatro años más-se puso en vigencia en el año 2006 en todo el país y declaró la emergencia en materia de posesión y propiedad de las tierras que tradicionalmente ocupan las comunidades indígenas del país. Como plan de intervención sobre esa emergencia, se ordenó por medio de la misma ley, la realización de un relevamiento técnico-jurídico y catastral de las ocupaciones "tradicionales, públicas y actuales" (Art. 2). A partir de esa norma se creó el Programa Nacional de Relevamiento Territorial de Comunidades Indígenas, que en la provincia de Río Negro comenzó a ejecutarse en el año 2007. El organismo designando como ejecutor en la provincia fue el Consejo de Desarrollo de Comunidades Indígenas ( $\mathrm{CoDeCl})$, y el Programa estuvo a cargo de un Equipo Técnico Operativo (ETO), que funcionó con representantes indígenas designados por la Coordinadora del Parlamento del Pueblo Mapuche.

3. Esta idea descansa en la premisa de que las personas participan en formaciones culturales diferentes, y parcialmente conectadas, en las que ellas son más que uno y menos que muchos (De la Cadena, 2015: 205-206). 
control, pero también pueden generar procesos de reflexión sobre las diferencias ontológicas y poner en valor aquello que permanece desconectado. $\mathrm{Al}$ concebir el proceso de traducción como una entextualización problemática de las conexiones parciales que resultan posibles en un determinado contexto histórico, entendemos también que ninguna traducción anula por completo las diferencias ontológicas ni logra fijar para siempre una única experiencia de mundo. Desde otro ángulo, consideramos que los sentidos de territorio percibidos por los mapuche como parcialmente desconectados pueden emerger en otras situaciones y contextos, en los que su potencial político para revertir las condiciones de desigualdad será posiblemente materia de nuevas reflexiones e inspiraciones (Kohn, 2002) entre quienes luchan por ello .

Los materiales que aquí analizamos se produjeron en el contexto de negociación entre miembros de comunidades y organizaciones mapuche de Río Negro y algunos ejecutores estatales de la ley de relevamiento indígena, específicamente en un taller convocado para que los mapuche - de diferentes edades, géneros, procedencias y competencias lingüísticas en su propia lengua-conversaran sobre lo que entienden por territorio, con el propósito de encontrar una definición más operativa e inclusiva. Sin embargo, aun cuando el taller no logró ese objetivo específico, permitió explicitar las concepciones compartidas por los participantes mapuche acerca de las diferencias radicales entre sus modos de ser en el territorio y las formas winka de habitarlo; y al hacer esto, reactualizaron juntos el mundo que sus antepasados lucharon por sostener, así como las esperanzas compartidas de poder volver a "levantarlo" para continuar siendo en y con la tierra.

En el transcurso del encuentro, ellos fueron espontáneamente actualizando ese mundo que en parte ya no es, que en parte sigue siendo y que fundamentalmente es anhelado. Como veremos en este artículo, los mapuche coincidieron en que ese mundo todavía es en sus memorias y en muchas de sus prácticas cotidianas, pero sobre todo, en que puede ser restaurado si se lucha por las condiciones necesarias para que esa reconstrucción sea posible. Al respecto, en este artículo queremos mostrar cómo a medida que las experiencias de cada participante mapuche fueron siendo relatadas desde los modos apropiados de hablar - según el arte de la oralidad mapuche y los conocimientos heredados - , la misma práctica de "estar conversando" devino en un modo particular de ejercer la política ("nos estamos poniendo en pie"). Y esto es lo que nos interesa contar.

\section{La producción del quiebre: antes y después del winka}

Si bien el intercambio entre los presentes intercaló el uso del mapuzungun (lengua mapuche) y el castellano, la sucesión de las distintas performances fue actualizando un marco de interpretación compartido, en el cual los sentidos literales de las palabras dieron lugar a otros socioculturalmente significativos desde la experiencia histórica y el arte verbal mapuche (Golluscio, 2006). En este marco, la categoría winka representó el quiebre entre el "antes" de las

4. El trabajo de la memoria en clave de restauración involucra una "ideología de la recuperación”. En coincidencia con

Joanne Rappaport, entendemos que esta no busca reponer la letra del pasado, "sino la reincorporación del espíritu de los antepasados en el contexto del presente" (Rappaport, 2005:31). memorias heredadas y el "ahora" de los participantes, y sobre este quiebre se estructuraron los recuerdos en el devenir del taller.

Este énfasis sobre recordar en clave de "lo que se perdió" nos invita a pensar el trabajo de la memoria como un trabajo de restauración (Ramos, 2016; 2017). ${ }^{4}$ Si restaurar es el acto de renovar, reparar y recuperar algo de un deterioro sufrido, cuando los grupos subalternizados emprenden un trabajo restaurativo 
de las memorias es porque evalúan sus contextos presentes como signados por algún tipo de "peligro" (Benjamin, 2001), de pérdida o de conflicto, y orientan la tarea de recordar hacia la comprensión de los quiebres para reconstruir desde ellos las relaciones interrumpidas. Así, el proyecto restaurador de la memoria no busca tanto producir una historia alternativa para reemplazar unas versiones por otras, sino romper la continuidad de los encuadres hegemónicos sobre el pasado. En esta dirección, la restauración no incorpora lo que fue ignorado a un continuum sin costura; más bien, identifica rupturas y quiebres para construir, desde estos, nuevas continuidades (Wolin, 1994). En breve, la tarea de restauración de la memoria combina dos propósitos: por un lado, "el de reconstrucción, lo que realmente sucedió en el pasado, reponiendo los eventos negados por los relatos hegemónicos; por el otro, reconstruir marcos de interpretación sobre el pasado en términos culturalmente significativos y relevantes para sus proyectos políticos en el presente" (Ramos, 2016: 64).

En el transcurso del taller, los quiebres fueron identificados como distintas formas de intromisión del winka: la mentira y la imposición. Formas de violencia que respectivamente produjeron rupturas en la circulación de la palabra mapuche y en el movimiento de las personas.

Las mentiras traídas por el winka, el silencio en el que se sumió la tierra, el alambre y la nostalgia de los campos abiertos son algunos de los tópicos con los que se describe la ruptura más amplia y profunda que trajo consigo el despojo territorial. ¿De qué maneras la memoria mapuche articula pasado y presente al producir quiebres específicos entre un antes y un después? Si bien esta idea de quiebre ya ha sido trabajada en varias oportunidades (por ejemplo, Ramos, 2005), nos interesa resaltar aquí el rol constitutivo que adquiere en la producción de las memorias mapuche.

Por un lado, al estructurarse a partir de un quiebre - específicamente, en alusión al producido por la invasión estatal sobre su territorio-, la memoria es concebida por las personas mapuche como un trabajo de restauración de ese mundo deteriorado, por eso, su tarea no se limita a la mera puesta en común de recuerdos. El trabajo de la memoria es, principalmente, el de "levantar las palabras antiguas" y, con ellas, volver a producir ese mundo donde las personas mapuche pueden desarrollarse como che (gente) en sus territorios. "Levantar las palabras antiguas" es un modo de concebir la memoria diferente al de las epistemologías modernas, puesto que la práctica de "levantar" tiene una función performativa de restauración que le es inherente. Se trata de recuperar la capacidad personal y colectiva de intercambiar experiencias entre seres humanos, pero también entre estos y otros seres no humanos (montañas, lagos, animales). En ese mundo de palabras (dungu), las montañas, los lagos o los animales - entre otros elementos del entorno- también se involucran en conversaciones con los humanos - por medio de señales, visiones, sueños o intercambios rituales-. Para que esas palabras vuelvan a levantarse, el trabajo de la memoria también exige un compromiso vinculante con las formas ancestrales y apropiadas de hablar. La habilidad de "hablar bien" o "con buenas palabras" refiere a la competencia lingüística y epistémica que ciertas personas especiales poseen para interactuar como lo hacían los antiguos con otras personas y con el entorno, pero sobre todo, es el medio privilegiado para traer al presente - sostener o producir - ese mundo que tanto es un pasado en deterioro como un futuro anhelado.

Por otro lado, la idea de quiebre inscribe la memoria en un metarrelato común a todos los mapuche, uno en el que la situación colonial impregna de sentidos 
5. El término winka no solo define tipos de personas según su origen, sino también según sus comportamientos. Por eso también puede ser utilizada para calificar ciertos modos de actuar entre las mismas personas mapuche: "estamos awinkados", "el winka impone, por eso buenas cosas no hablamos más nosotros".

6. En adelante, usamos las iniciales de las personas para señalar que la cita corresponde a uno de los participantes del taller.

7. Los ngutram son historias evaluadas como verdaderas por los mapuche que han sido o son incorporadas como entextualizaciones en el flujo de la transmisión intergeneracional (Cañuqueo, 2004; Golluscio, 2006; Golluscio y Ramos, 2007; Ramos, 2010). específicos a las experiencias históricas mapuche desde fines del siglo XIX (Mariman Quemenado, 2014). Desde este ángulo, la memoria mapuche también se constituye frente a ese otro colonizador ("para que el winka sepa") con el fin de impugnar las prácticas impuestas - ya sean estas "winkas" o "awinkadas" $-{ }^{5}$ y la condición colonial que se reproduce hasta nuestros días bajo el amparo de relaciones de violencia sustentadas en una jerarquización naturalizada. Cuando las personas mapuche se juntan para compartir las experiencias heredadas o vividas suelen identificar algunas de esas prácticas impuestas como señalamientos temporales del inicio de una pérdida progresiva del control sobre sus vidas cotidianas y sobre la historia de su pueblo. Pero esos quiebres también son los puntos de referencia necesarios para restablecer los principios ancestrales en los que debe estar basado todo proyecto autonómico sobre la historia, el conocimiento y el territorio mapuche. Al estructurar los relatos en un antes y un después, la memoria mapuche asume su tensión constitutiva, esto es, la tensión entre privilegiar la denuncia de la situación colonial en los lenguajes administrativos y epistémicos impuestos y continuar las luchas de sus ancestros comprometiéndose con un antes de autonomía ontoepistémica y de soberanía territorial.

\section{El winka mentiroso: el poder de la palabra}

Vino el turco y trajo de todo, sacó los animales, trajo el vino, los emborracharon, les robó, los destruyó, mintió el winka. Con los alambrados, con el comerciante, con el alcohol y con las deudas (DC) ${ }^{6}$.

(...) el weñefe (ladrón) también entró ahí (TE).

El winka es el que introduce la lógica de la mentira en un mundo organizado por los mensajes verdaderos, la comunicación y los acuerdos de palabra. Este apartado muestra cómo se fue actualizando un marco de interpretación compartido a partir del quiebre que produjo la mentira del winka con respecto a un modo de relación territorial - entre las personas mapuche y con los ancestros y las fuerzas del entorno- basado en la lógica del "hablar bien".

$\mathrm{Al}$ iniciar los intercambios en el taller, DC introduce en mapuzungun dos $n g u$ tram ${ }^{7}$ interrelacionados entre sí y que sintetizamos a continuación.

El primer relato cuenta que "antes", cuando sus antepasados vivían "por acá", conversaban entre ellos y con los espíritus. Cuando vino el winka - "otra gente a sacar la tierra" - , los antiguos decían que vino también un "espíritu mentiroso" y que este era el "arma del winka". Los espíritus de la montaña avisaron a los mapuche que el winka "venía con mentiras" y con el propósito de "arrebatar la tierra". También anunciaron que para lograr ese objetivo iban a traer a los curas, quienes mentirían a los caciques. "Estaba enojada la gente de antes". "Volvieron a la montaña". Fue allí, en la cima, donde un machi (mediador entre los espíritus y los hombres) les dijo que todo se había perdido porque "toda clase de mentiras tenían (los sacerdotes cristianos), de traición tenían". Por eso pasaron hambre y murieron muchos curas en esta tierra. Así, a través del machi, escucharon hablar a la tierra, hablar a la montaña. Permanecieron en la cima y cuando el winka "fue a la siga", no pudo subir y murió en el camino.

El segundo relato inicia con el consejo (ngulam) de los antiguos: "nunca juegue en la montaña, no juegues en el lago, decían". Los antiguos enseñaron "a respetar, a no hablar malas cosas", a hacer rogativa y a "hablar bien cuando entraban a un lugar", por ejemplo, a hacer "rogativa si vamos a cortar leña". 
El winka, en cambio, "de todo anduvo haciendo", por eso "había animales que gritaban y hoy no gritan más, se terminaron los grandes animales". Al finalizar este segundo ngutram, otra de las participantes agrega: "Así está pasando acá, muchas cosas malas hay, muchas cosas malas por todas partes (...) Nosotros estamos entrando con las cosas del winka, por eso estamos así", "antes solo como familia estaba la gente, ahora como perros nos tratamos" (FP).

En estos relatos, la mentira del winka introduce un modo de actuar y de relacionarse con el entorno contrapuesto a las formas mapuche de interactuar con los seres del mundo. Las "buenas palabras" o el "hablar bien" (Golluscio y Ramos, 2007) es una práctica mapuche - transmitida a través de consejos antiguos - de intercambio comunicativo entre las personas y las fuerzas del entorno basada en una relación de mutuos cuidados, escucha atenta y respeto. En oposición al "hablar bien", el winka trae la mentira y las relaciones irrespetuosas, representadas en la idea de "jugar" con la montaña o con los lagos, como equivalente a no considerar seriamente las reglas de los lugares por los que se transita. Por lo tanto, el primer quiebre en la continuidad de la historia mapuche se inaugura como una ruptura de los códigos establecidos por los antiguos y de los pisos normativos que configuraban las formas de habitar el territorio. El "antes" es aquí "ese tiempo en que la gente era muy sabia, en el que la gente solo hablaba en mapuzungun, en el que hacían grandes encuentros y en el que parlamentaban los mayores" (FP).

Al finalizar los ngutram, TE se presenta a sí misma diciendo que ella vivió en la ciudad, que le resulta difícil hablar en mapuzungun y que no sabe escribir en papel. Entonces otro de los participantes la interpela: "en lengua (mapuzungun) nomás hablemos". TE responde intercalando frases en castellano y en mapuzungun: "eso está mejor, porque la lapicera y el papel engañan mucho, por eso mi abuelo y mi abuela sabían decir: gente mala, ladrón, gente mala mentirosa, decían ellos, no hable idioma winka, mala gente es".

Este acuerdo metacomunicativo en torno al código lingüístico no solo concluye la idea del ngutram (el winka trajo la mentira), sino que también confirma la importancia de hablar en mapuzungun para "levantar las palabras antiguas" y sus códigos sobre "el hablar bien". A partir de entonces, el evento del taller es recentrado en los marcos de interpretación heredados y en la empresa de restaurar los sentidos que el winka puso en peligro. Por eso, cuando FP introduce la pregunta: Fey muta chumnegechi may liftutuay taiñ longko liftutuay taiñ piwke taiñ rakizuam (Entonces ¿cómo pues limpiaremos nuestras cabezas, limpiaremos nuestros corazones, nuestros pensamientos?), las respuestas coinciden en subrayar el poder restaurador de la palabra:

(...) las buenas palabras nos darán buenos pensamientos. No nos estamos gobernando solos nosotros, no nos mandamos solos, nos mantienen cuidando, están (los seres espirituales de los ancestros y el entorno).

(...) tenemos que mantener el nguillatun (rogativa mapuche) y buenas palabras tendremos nosotros.

Muchas palabras se perdieron, pero volverá a hablar la tierra, a conversar la montaña, los árboles. Los antiguos dijeron que en esos lugares hay conversación, se va a conocer el espíritu, volverá a estar el espíritu y se podrá volver a aprender. Estamos levantando nuestras palabras, y está parado (en pie) acá.

Es en estas concepciones mapuche sobre el lenguaje en que la contraposición entre el hablar bien mapuche y la mentira winka adquiere su profundidad interpretativa. Tomando como referencia los trabajos de Magnus Course (2012) 
8. La fuerza esencial e inmanente del mundo (newen) -instanciada en todo lo que existe- se manifiesta en el fluir de la "palabra" (dungu), y, en esta continuidad reside el exceso o la potencialidad del lenguaje (Course, 2012). y de Marcelo González Galván (2015), entendemos que el comportamiento humano adecuado (centralmente el "hablar bien") es aquel que, subordinado a las fuerzas (newen $)^{8}$ del mundo, se alinea con ellas. Desde este ángulo, un comportamiento adecuado es uno consecuente con el hecho de que "no nos estamos gobernando solos nosotros, no nos mandamos solos, nos mantienen cuidando".

Por un lado, las distintas expresiones de la palabra - ya sean estos tan dispares como los relatos históricos ngutram, el habla de la montaña, el grito de los animales, etc. - "son devenires o instancias de newen" (Course, 2012: 10). Según este autor, el mapuzungun existe en una continuidad inmanente con las fuerzas del mundo, por eso es mediante el intercambio de la palabra que los seres y las cosas de este mundo se constituyen y revelan entre sí. La palabra tiene poder performativo sobre el mundo ("estamos levantando nuestras palabras, y está parado [en pie]) acá"), porque es, de alguna manera, la continuación de las fuerzas que lo constituyen. Por otro lado, y en relación con ello, la percepción de una práctica como "mentira" pareciera no referir tanto a una distorsión con respecto a la realidad, sino a un alejamiento con esas formas adecuadas de comportamiento. Una de las acepciones que el mapuzungun tiene para la idea de verdad es la de mupin ("decir la verdad") - opuesta a koyla (mentira) -, cuyo énfasis está en la evaluación social de la verdad según los distanciamientos en las formas de actuar o las similitudes de ser (González Galván, 2015). En esta línea, los comportamientos winka ("jugar", robar, invadir, sacar la tierra) representan el máximo distanciamiento con las prácticas mapuche $y$, por ende, con la verdad o los "buenos pensamientos". Finalmente, y tal como expresó TE en el taller, "los que quedamos todavía podemos hablar mapuzungun, todavía nos tiene en la tierra füta chao (gran padre)", es a través de la palabra que las personas mapuche podrán continuar siendo o volver a ser en la tierra.

Ahora bien, el poder de la palabra también reside en la memoria, esto es, en la presuposición y la recreación de los sentidos convocados por la idea de un "antes" (Foley, 1995). Ese antes no es un lugar preconcebido al que se quiere retornar, sino una fuente de índices desde los cuales reconstruir marcos de interpretación culturalmente significativos en el presente. El taller es un evento orientado en esa dirección, puesto que sus participantes están acordando entre sí cómo entender el aquí y el ahora de su ser juntos por medio del intercambio de trayectorias familiares y personales. En los sentidos compartidos sobre esos entonces y allí fueron identificando las claves para comprender sus relaciones en el presente y hacia el futuro. Podríamos decir que los participantes fueron acordando formas de interpretar el territorio tomando como material de reflexión los modos en que cada uno de ellos entiende que sus antepasados negociaron y acordaron el ser juntos en el pasado. Parafraseando a Doreen Massey (2005), el territorio vivido por los antepasados es reconstruido como lugares de encuentro donde distintas trayectorias se interceptaron y confrontaron el desafío de responder colectivamente acerca de cómo ser juntos entre humanos y con los no humanos. Es así que, en el transcurso del taller, se seleccionaron ciertos hechos pasados como índices de un modelo de relacionalidad con el entorno (con los humanos y los no humanos) centrado en el potencial de la palabra para establecer vínculos y pactar compromisos. Desde este ángulo, el marco de interpretación acordado es también la expresión de una política espacial acerca de cómo deben ser entendidas las negociaciones involucradas en la constitución de un "nosotros-gente de la tierra".

Como dijimos arriba, el "antes" emerge como tal cuando el winka irrumpe en el devenir de la palabra mapuche con sus mentiras y sus prácticas irrespetuosas. 
En esos tiempos en que "la gente era sabia", los antepasados tenían muchos conocimientos sobre el entorno y sabían cómo utilizarlos en distintas actividades productivas. Los saberes antiguos no solo incluyen conocimientos específicamente técnicos, sino también acerca de cómo las personas y los no humanos (los "espíritus" de los lugares) se conocían e interactuaban entre sí a través de las buenas palabras.

En esta dirección, los participantes del taller recuerdan que los compromisos productivos se establecían por medio de distintas prácticas de reciprocidad entre vecinos y parientes - a veces distantes - . Por ejemplo, el yawketumean o ayuda mutua ("si viviéramos en comunidad viviríamos ayudando uno al otro cuando el hermano necesita"); el rokiñ o llevarse provisión ("carneaban un animal en un puesto y allí estaba el peñi: 'Voy a invitar al peñi que venga y ayude porque tiene que llevarse carne"'); el trafküntun o intercambio ("desde allá vinieron a buscar semilla... al año le pagaron con yeguarizos"). ${ }^{10}$

Esa misma reciprocidad se practicaba con los no humanos, de quienes también dependía el éxito de los emprendimientos productivos. A partir de la premisa compartida de que "acá en la tierra hay un montón de palabras, antiguas palabras de la tierra", DC recuerda que la gente antigua sabía escuchar a la montaña para saber si iba a llover o nevar; y EC cuenta que, a través de sus sueños, la madre supo que "iba a venir una sequía muy grande en la zona". $\mathrm{Al}$ recordar que la tierra (representada en sus elementos) emite palabras que las personas pueden escuchar, TE desplaza el tópico hacia los pülli o espíritus que andan en ella. Entonces las intervenciones de los distintos participantes se organizan en una enumeración de los distintos pülli que existen en la región. A medida que los nombran, actualizan los conocimientos que recibieron de sus antepasados acerca de las características distintivas de esos espíritus y sobre los modos en que estos pülli se relacionaban entre sí. Resumimos este prolongado intercambio de turnos en la siguiente enumeración:

1. A veces era necesario solicitar la ayuda de expertos (personas especiales) en el manejo del espíritu witranalwe para que éste cuidara las ovejas, las chivas y los caballos.

2. El kolümakün llega saltando y también cuida los animales a su dueño, para evitar que se los lleve el espíritu kalku.

3. Distintos espíritus andan en todos lados, en los montes, en los cerros, en el agua, en los lagos.

4. Algunos espíritus andan cuidando a los chicos cuando juegan, y lloran si anda mal el hijo de uno.

5. También está el willifüre que viene del sur.

6. No hay que "jugar" con esos lugares, se enojan los espíritus, se enoja el cuidador del agua.

7. Al mediodía y cuando se está haciendo de noche, andan los malos espíritus como grandes remolinos.

8. Al mediodía no hay que andar porque anda el kolümaküñ y te topa (te encuentra). Es como un remolino que viene saltando.

9. En los menuko, ojos de agua, se siente bramar un vacuno abajo, es el rey del agua.

10. Todo ojo de agua tiene su rey, algunos tienen caballos, ovejas, carneros, incluso en la zona de Marako hay un mapuche bañándose en la noche.

Las personas antiguas no solo los veían, sino que también sabían cómo relacionarse con ellos para establecer acuerdos de mutuo respeto. En primer lugar, destacamos que las personas comparten los presupuestos generales en torno a la existencia de los pülli y de los protocolos para interaccionar con ellos de manera sabia, aun cuando suelen diferir sus experiencias con ciertos espíritus
9. Peñi es usado para referir a los hermanos mapuche en un sentido genérico. 10. La importancia que tienen las relaciones de reciprocidad en la construcción de vínculos sociales en las comunidades mapuche fue profundamente trabajada por Sabine Kradolfer (2001). 
en particular, en cuanto a las formas de nombrarlos y al conocimiento producido en torno a ellos. Esto implica que el conocimiento sobre el lugar es siempre situado, experiencial y afectivo (Basso, 1988). En segundo lugar, y volviendo al eje de nuestro argumento, que la expertiz para relacionarse con el medio involucra conocimientos de relacionalidad basados en la palabra. Este énfasis también va emergiendo en el transcurso del taller, específicamente cuando los participantes subrayan la importancia de saber cómo comunicarse con cada uno de los espíritus en las distintas circunstancias de encuentro. $\mathrm{Al}$ respecto, uno de los participantes cuenta que alguien construyó una casa sobre un menuko (ojo de agua), y que desde entonces no solo tuvo miedo sino que no pudo dormir. Este efecto negativo es comprendido por todos los presentes como consecuencia de no haber hablado primero con el pülli del lugar para pedirle permiso, o por no haber respetado su lugar al construir una casa justo allí. Ignorar la práctica de pedir permiso hará que, como afirmó TE, "el pülli no lo deje tranquilo a uno". Cuando en la actualidad las personas circulan, se detienen y producen en el territorio también deberían conocer, interactuar y pedir permiso a las fuerzas instanciadas en la naturaleza, porque los pülli siguen estando allí:

$$
\begin{aligned}
& \text { PC: petu müley ta pülli (todavía hay espíritus) } \\
& \text { DC: petu müley mongeley (todavía están vivos) } \\
& \text { TE: mongeley, claro (están vivos, claro) }
\end{aligned}
$$

La importancia de la palabra para acordar compromisos vinculantes ha llevado a que la idea del "permiso" deviniera en un marco general acerca de las relaciones con el territorio. El pedido de permiso no sólo crea vínculos con los espíritus, sino que también ha sido una práctica recurrente para sellar distintos pactos de coocupación territorial entre las personas.

El acuerdo de palabra emerge en esta dirección cuando uno de los participantes recuerda que en la comunidad de su abuelo - la misma de donde él provenía - se había asentado, a principios de siglo, la familia Nañküleo. Cuando esta familia "llegó corrida" con sus animales, la familia Longkonao, que ya estaba en el lugar, le dio permiso para asentarse allí. Por su parte, AQ también recuerda que la gente "que venía ambulante paraba en la casa, pedía permiso para estar y así se fue poblando la zona".

Estos últimos ejemplos nos muestran que el poder de la palabra es también el fundamento de los acuerdos, las negociaciones y los compromisos vinculantes entre las personas, y entre estas y los seres no humanos con los que cohabitan un mismo territorio.

El marco interpretativo que se fue actualizando en el transcurso del taller se estructura a partir de la oposición de dos dispositivos de producción del espacio contradictorios entre sí: por un lado, la mentira como "arma del winka", por el otro, el poder de las buenas palabras de la "gente de antes". Hasta aquí, mostramos cómo los participantes del taller fueron construyendo sentidos, como los movimientos de un espiral, en torno a un mundo hablado en el que se destaca el poder de la palabra. La palabra verdadera es el hilo con el que se tejen las relacionalidades constitutivas del wallmapu o territorio mapuche como un modo de ser juntos en la tierra. 


\section{La imposición del winka: la importancia del "campo abierto"}

El winka impone, por eso buenas cosas no hablamos más nosotros (...) Malas cosas trajo el winka, llegó el winka, vino a traicionar el winka (DC)

El winka es el artífice del despojo, el que se queda con los campos y el que trajo el alambre, esto es, el que impuso las fijezas y el arrinconamiento del mapuche en el territorio. En este apartado nos detenemos en los sentidos que van emergiendo en torno a la noción de territorio cuando la reflexión sobre el pasado se organiza a partir del quiebre que produjo la imposición del winka con respecto a una historia de movimientos.

En los relatos mapuche, el movimiento - entendido aquí como la gente circulando en el territorio - es un concepto multiacentuado (Voloshinov, 1992), en el que confluyen valoraciones disímiles. Esto responde a que en él se condensan historias y experiencias muy diferentes, como por ejemplo, las de persecución por parte de los ejércitos nacionales (argentino y chileno); de huidas a la cordillera en las que se encontraban con los espíritus de las montañas o de sus antepasados; de desplazamientos forzados durante las campañas militares (deportaciones y encierros); de largos peregrinajes de regreso en búsqueda de familiares y de lugares donde vivir tranquilos al finalizar las campañas; de tiempos en los que las personas deambulaban sufriendo de hambre y sed; de traslados en búsqueda de mejores lugares; de cruces por la cordillera por razones económicas o políticas; de viajes para asistir a parlamentos entre distintos grupos; de marchas de varios días para intercambiar productos, entre tantas otras.

Durante el taller, las formas diferentes en que se nombra el movimiento implicitan esos énfasis y acentos disímiles: "andaba deambulando", "venir de la corrida", "disparaban", "recorrían" o "no tenían paradero fijo". ${ }^{11}$ Pero aun cuando refieren a historias tristes de persecución o a historias de libertad y autonomía, esas memorias de las "andanzas" - experiencias de marcha heredadas o vividas $-{ }^{12}$ fueron entextualizadas en el arte verbal mapuche y devinieron constitutivas de la subjetividad mapuche. Esto lo vemos particularmente cuando los participantes eligen presentarse a sí mismos contando de "dónde vinieron" sus antepasados. En algunos casos, la marcha está claramente marcada como un desplazamiento forzado por los años de conquista militar y por las políticas de sometimiento estatal. Así, por ejemplo, decía uno de los participantes de la comunidad Cañumil:

mi abuela pudo contarle a la gente cómo se disparaban, cómo se alimentaban, no podían hacer fuego porque lo llevaban cerca (los perseguían desde cerca), había que matar los caballos para saciar la sed, poner a hervir un cuero viejo para poder comer (...) Cuenta que su abuelo siendo bebé queda huérfano porque el malón mata a su familia, entonces parte de la zona de Azul (Buenos Aires) con su hermana hacia Chile donde se cría y adopta el apellido Cañumil, y de allí viaja a Argentina a la zona de Karüwe, donde hay un corral de piedra $(\mathrm{AQ})$.

En otros casos, los contextos de persecución o de pobreza son silenciados para poner en valor la mayor libertad de movimiento que tenían sus antepasados sobre el territorio antes de las campañas militares de los Estados, primero, y antes de la imposición de los alambrados, después. Con estos énfasis, los participantes reconstruyen los recorridos de sus antepasados y sus respectivos
11. Aquí es importante subrayar que, en Argentina, las políticas estatales tendieron sistemáticamente hacia el despojo, la expropiación y el desplazamiento de las personas mapuches de sus territorios (Briones y Delrio, 2002; Delrio, 2005; Ramos, 2010; Pérez 2016).

12. Sobre este tema trata el trabajo de Ana Ramos y Sabine Kradolfer (2011). 
13. El tuwün es el lugar concreto donde nace una persona, $y$ donde se solía enterrar la placenta - práctica fuertemente silenciada y prohibida durante el siglo XX-. Por eso, el tuwün es entendido como el origen personal y familiar constituido en el territorio (Cañumil y Ramos, 2016). En mapuzungun, el término tuwün generalmente se emplea como un verbo que significa "venir desde" pero también se puede usar como sustantivo para referirse al lugar de origen de cada persona mapuche (Di Giminiani, 2015). lugares de tránsito y de detención transitoria. TE relata, por ejemplo, que su abuela llegó por el paso cordillerano de Anükon, "por toda esa parte se recorrió antiguamente, los mapuches no tenían paradero fijo"; EC recuerda que su mamá le contaba que ella "nació en la andanza" porque sus abuelos eran caminantes, "no tenían paradero", y que durante la epidemia de 1930 dejaron el lugar en el que se habían detenido, para llegar entonces a Michiwaw, donde nacieron él y sus hermanos.

De los distintos relatos - en los cuales los hablantes entretejen las trayectorias familiares con las llegadas al lugar donde cada uno nació-, destacamos, por un lado, el detalle con el que se reconstruye el recorrido al explicitar cada uno de los nombres de los lugares por donde fueron pasando (por ejemplo, EC nombra Raihuau, Curauf, Michihwaw). Por otro lado, el valor afectivo y de pertenencia que aún tienen esos lugares de tránsito, el cual se actualiza cuando la memoria vuelve a ellos para encontrarse con los vestigios de los antepasados ("donde llegaron por primera vez todavía está el reparo de piedra amontonada"). Finalmente, la asociación frecuente entre el nacimiento de sus antepasados y el hecho de estar en movimiento, tal como expresa EC al decir que su madre "nació en la andanza", o que otros subrayan cuando cuentan que alguno de sus antepasados nació en una laguna, en un pozo cubierto con ramas de neneo o en un cuero de guanaco mientras estaban en tránsito. Estas recurrencias en las formas de relatar las trayectorias familiares dan cuenta de la importancia que tienen las experiencias de marcha en la configuración de quiénes son los mapuche en la actualidad.

Por eso el tuwün, 13 "el lugar de origen que a uno lo forma en una relación especial con el territorio", adquiere en los relatos un sentido nostálgico. La mayor parte de las personas mapuche, como consecuencia de sus movimientos, no se encuentra habitando en el sitio de su tuwün, pero ese lugar de nacimiento sigue siendo constitutivo de quienes ellos son. Así como la abuela de AQ "jamás olvidó que era de ese lugar", TE expresa los sentimientos que volver o recordar su tuwün despierta en ella: "se alegra y llora el ngümngumangetuy tañi ñuke mapu akuakutuy tañi püñ̃eñ (llora nuestra madre tierra, volverá mi hijo); se juntan allí todos los espíritus de los abuelos todos los espíritus de la tierra, todos los que se han ido". En tanto recuerdo, el tuwün adquiere los sentidos de una historia de movimientos porque es el lugar en el que la historia personal se entrama con las trayectorias de marcha de quienes le antecedieron a uno. En tanto presente, el tuwün define la subjetividad del ser mapuche porque es el lugar que uno siempre lleva consigo - las influencias de los ancestros y de las fuerzas de ese lugar continúan moldeando las potencialidades y predisposiciones de la persona (Di Giminiani, 2015).

El hecho de poner en valor el movimiento no contradice los sentimientos de estar fijados a un lugar de origen sino que, por el contrario, los confirma, puesto que se trata de un modo de circular el territorio que es articulado conceptualmente alrededor de los principios ontológicos de tuwün. Este último presupone la naturaleza agentiva de la tierra ancestral (Di Giminiani, 2015) que sigue moldeando las trayectorias en marcha de una persona. Tener un tuwün implica una predisposición a actuar en relación con las fuerzas que lo formaron a uno. Por esta razón, el tuwün es una manera de entender el enraizamiento en el territorio, sin importar los lugares que uno transite durante su vida. En contrapartida, el winka siempre será extranjero en el territorio, porque sus modos de circular y de relacionarse con él no resultan de un tuwün. 
Hasta aquí hemos querido mostrar que las formas de subjetivación mapuche en el presente se estructuran en historias heterogéneas de movilidad. Un movimiento que, aun cuando es interpretado como impuesto por la colonización, deviene, de todos modos, constitutivo del ser. Este desplazamiento de sus sentidos impuestos hacia otros más biográficos y afectivos es el que permite que el "antes" sea valorizado como un tiempo en el que el territorio podía ser libremente transitado. En este último énfasis, en el que nos detendremos a continuación, el movimiento de las personas representa un territorio en el que la propiedad privada todavía no había llegado a imponerse y, en consecuencia, un "antes" en el que las personas aún tenían el control sobre la configuración espacial de sus marchas y detenciones. Estos intersticios de autonomía territorial son representados en las memorias en la noción de "campo abierto" (sin alambrados). ${ }^{14}$

Como ya anticipamos, al finalizar las campañas militares a fines del siglo XIX, los mapuche emprendieron largos recorridos (a veces de varios años) para encontrar un lugar donde "vivir tranquilos". Este regreso ocurre en un contexto histórico en el cual el espacio se había transformado en un territorio parcelado en latifundios y estancias de propiedad privada. Sin embargo, las memorias subrayan que, a pesar de estas avanzadas de la propiedad privada, los antepasados aún encontraban sitios de "campo abierto": "porque nadie era dueño de la tierra, como él decía, llegaron a Michiwaw, encontraron buen pasto y se quedaron"; los padres "se fueron y allá quedaron, encontraron un lugar ahí y se quedaron" (EC).

La lógica del "campo abierto" opera, entonces, como marco de interpretación de un "antes" signado por la valoración del movimiento y una noción amplia de territorio. Esto es, un territorio definido por los lugares que la gente transitaba y conocía; un territorio en el que las fuerzas y espíritus de sus elementos establecían vínculos de reciprocidad y entendimiento con los caminantes: "mientras estamos en tránsito alguien nos va a cuidar" (como, por ejemplo, ciertas fuerzas instanciadas en piedras, luces, animales).

Es en este marco que adquieren sentidos especiales los recuerdos sobre las formas en que las personas antiguas se vinculaban entre sí mientras se movían aún con cierta autonomía. En diferentes momentos de la reunión se fueron actualizando diversas prácticas de relacionamiento sostenidas por esa libertad de tránsito, como "ir de caza", los traslados de los animales a lugares de "veraneada" y los viajes para intercambiar productos. Los recuerdos de estos viajes, y particularmente el hecho de que estos se realizaran a través de los "campos abiertos", son parte de una memoria que pone en valor la libertad de movimiento.

Con respecto a la distribución del tiempo en épocas de caza y de cosecha, o de veranada e invernada, TE menciona que ella llegó a vivir en los tiempos de "campo abierto" cuando su padre y su madre "iban a otra parte a andar cazando guanacos y choiques". Recuerda que algunos de sus hermanos nacieron en esos recorridos "porque las mamás de antes en cualquier lado tenían sus hijos, se iban en pilchero ${ }^{15}$ (donde llevaban agua en zurrones de cuero) y capaz que cuando volvían traían un bebé". Regresaban de estos viajes después de un tiempo, cuando se terminaba la caza, cargando charqui, cueros, pieles y "mercadería para todo el año". Cuando llegaba el tiempo de la cosecha, no salían más. La repartición del territorio en áreas de invierno y de verano para los animales también se asocia con la libertad para diseñar los itinerarios anuales: "Ellos iban recorriendo donde era mejor un año".
14. La idea de "campo abierto" nos permite entender cómo el territorio es sociopolíticamente tematizado reuniendo pensamientos y memorias en configuraciones creativas, históricas y particulares (Cresswell, 2004).
15. Son caballos usados por los arrieros como cargueros y se usan para llevar las "pilchas" (ropas y cobijas) u otros elementos. 
16. El rodeo de animales consiste en lograr que las majadas retornen a un sitio determinado luego de pastar, para lo cual se les inculca que transiten por sectores determinados que los pobladores acuerdan colectivamente (mallines, arroyos, pozos de agua, lomas, entre otros) y que son delimitados por medio de mojones (referencias físicas naturales o construidas).
Como vimos antes, el intercambio de productos, o trafküntun, también podía implicar "varios días de viaje" hacia parajes distantes donde poblaban familiares o conocidos. Al respecto, EC recordaba uno de los viajes de trafküntun que habían realizado sus abuelos: "desde allá vinieron a buscar semilla... hicieron varios días de viaje y cuando llegaron acá no tenían plata y como por acá tenían familiares le fiaron la semilla, al año le pagaron con yeguarizo".

El paisaje de los campos abiertos también se fue conformando por los trayectos de los animales de pastoreo y la práctica del rodeo. ${ }^{16}$ Esta forma de pastoreo permitía que los vecinos turnaran entre sí los tiempos de viajar a otros sitios y los momentos de cuidar a los animales de los zorros o pumas: "Entre peñi se respetaban, ellos dejaban los animales tranquilos porque venían solos a su rodeo, los mapuches enseñaban los animales a rodeo"; "porque ante los animales se volvían solos al rodeo, no precisaba ir a buscarlos, no había campos alambrados". Recordando estas prácticas, TE actualiza el quiebre entre al "antes" y el "ahora" con la siguiente reflexión:

no había campo alambrado, sólo mojones por los que cada lindero sabía cuál era el lugar de ellos, y como eran tan comunitarios los amigos, los vecinos, los peñi, se decían "te encargo el animal, si pasa para allá corrémelo para acá"... iQué lindo sería estar en esa vida! Ayudarnos uno con otro. Pero está difícil, porque estamos awinkados.

En el curso de sus vidas cotidianas, tanto las personas como los animales producen los caminos, trayectos, texturas y contornos del territorio que practican. En otras palabras, el territorio percibido como "campo abierto" es producido por estos paisajes variables, cuando distintos movimientos pedestres van entramando una red enmarañada de huellas de tránsitos y encuentros que se constituyen en estaciones. Parafraseando a Ingold (2011), el territorio es tejido en el devenir de las vidas cotidianas y las vidas son tejidas en el territorio practicado.

Esos tiempos del "antes", en los cuales el movimiento por el territorio y las redes de vínculos sociales que este habilitaba y que en la actualidad se valoran positivamente, están representados en la figura del "campo abierto" como opuesta a la imposición de los alambrados que trajo el winka durante el siglo XX ("los mayores no tenían alambres"; "bueno, vos te vas a ir a asentar allá, era así la cosa, no existía el alambrado"; "en 1900 no había alambre por ninguna parte pero había gente").

Como contrapunto, el alambre trajo el despojo, la emigración y el trabajo asalariado. Gran parte de los intercambios de experiencias en el transcurso del taller se centraron en las trayectorias laborales como peones de estancias, en la emigración a las ciudades en búsqueda de trabajo y en el despojo de sus tierras. Los participantes reconocen sus propias historias en las del otro ("la misma historia que se está contando acá le pasó a la gente nuestra también") para subrayar la reiteración del proceder del winka con el engaño, la complicidad del Estado (en las agencias de la "policía fronteriza" y las leyes) y la imposición de los alambrados.

y al abuelo lo engañaron por la famosa solidaridad, el mapuche era el más bueno que existe, bueno de hecho lo seguimos siendo. Al abuelo le decían "estoy mal, tengo seis, siete hijos", "sí, tomá, pasá el invierno este", decía; cuando llega Mohana a Chenqueniyen se le rompe el carro por ahí, iba para Portezuelo, ahí tenía un pariente que lo había llamado, iba con toda su familia. ¿Quién lo socorrió? El viejo Cañumil dijo 
“bueno, háganle un rial de chapa parada”. Así se quedó, se hicieron compadres. Ya ahora Mohana tiene todos los campos alambrados, con complicidad del Estado (AQ).

La misma historia que se está contando acá le pasó a la gente nuestra también, ahí están los Pérez García, se quedaron con todo el campo y a la gente le quedó la pura piedra, y ahí está la gente amontonada... y muchos nos fuimos a la ciudad (FP).

Como dijimos al inicio de este apartado, la experiencia de movimiento atraviesa los relatos históricos de la memoria mapuche con sentidos muy diferentes entre sí. Por un lado, refiere a experiencias de violencia y subordinación (como por ejemplo, las persecuciones de los ejércitos a fines del siglo XIX y los desplazamientos hacia las ciudades forzados por los alambres en el siglo XX). Pero, por otro lado, en su valoración como "campo abierto", el movimiento define una experiencia territorial propiciada por reciprocidades entre parientes y vecinos. Reciprocidades que se fundamentan en los principios conceptuales más amplios del tuwün, los cuales contraponen los modos de actuar mapuche con los del winka. Los mapuche circulan el paisaje siendo parte del territorio que los formó de una determinada manera como personas (" $i Q u e ́$ lindo sería estar en esa vida! Ayudarnos uno con otro. Pero está difícil porque estamos awinkados").

\section{Conclusiones: territorio, palabra y movimiento}

Analizar la memoria prestando atención al proyecto restaurador que le subyace nos lleva a identificar los quiebres, deterioros y rupturas en los que se posicionan las personas para enunciar un "antes" en articulación con las agendas políticas de reflexión en el presente. Entendemos que aquellos aspectos de los "tiempos antiguos" que colectivamente se iluminan y ponen en foco operan como índices de contextualización en el presente. Esto quiere decir que las memorias de un mundo hablado y las memorias de un mundo en movimiento no actualizan saberes exclusivamente heredados del pasado, como tampoco conocimientos exclusivamente recreados desde el presente (Kohn, 2002). Es más bien en la dialéctica entre pasado y presente donde el recuerdo del "antes" actualiza sus sentidos: por un lado, como contraposición a un presente evaluado como deterioro, por el otro, como resguardo de imágenes del pasado valoradas por su potencial político para restaurar los mundos anhelados.

A medida que estos marcos iban cobrando centralidad en la significación y valoración sobre lo dicho en el taller, la noción de territorio refirió menos a una extensión limitada y medible de tierras y más a los eventos espaciotemporales (Massey, 2005) en los que los antepasados fueron negociando sus maneras de "ser juntos" a través de la historia. En este sentido, creemos que la contrapropuesta de las personas mapuche consistió en poner en común los cimientos generales para cualquier construcción colectiva de una noción de territorio. Por un lado, una posición denunciante frente a los engaños y a los despojos realizados por el winka y la imposibilidad del Estado de reparar alguna deuda histórica sin revertir primero los procesos de deterioro. Por otro lado, la percepción presente del territorio como relaciones que deben ser restauradas. Esto llevó al reconocimiento colectivo del poder político de la palabra (dungu) para volver a "levantar" ese mundo que sus antepasados tantas veces reconstruyeron en el pasado.

Ellos destacaron la importancia de "levantar las palabras antiguas" para volver a comunicarse entre sí y con los elementos no humanos del entorno, y 
en relación con ello, el valor de un territorio practicado en ejercicio de sus derechos de autonomía y de tránsito. Defender o recuperar un territorio es, entonces, sostener o restaurar vínculos y relaciones, acuerdos y compromisos entre las personas y otros no humanos donde se instancian las fuerzas.

$\mathrm{Al}$ ampliar la discusión en torno al territorio, los participantes no dejan de lado sus reclamos concretos y materialmente situados sobre ciertas áreas perimetrales, sino que plantean un desafío mayor: empezar a traer a las arenas políticas los fundamentos ontológicos que permanecen en las sombras de las traducciones usuales de territorio.

En un país como Argentina, en el que el lenguaje estatal de la propiedad, las lógicas epistémicas de la política moderna y los estereotipos hegemónicos sobre el indígena han inhabilitado cualquier discusión sobre territorio - que no sea en términos exclusivamente físicos y perimetrales-, el hecho de que los participantes de este taller hayan puesto en primer plano sus propios lenguajes y fundamentos ontológicos en el marco de una negociación con el Estado es, en sí mismo, un hecho político. Trabajos de memoria como el que surgió en este taller son los que nos llevan a concluir que la puesta en valor de los tiempos antiguos, más que buscar el retorno mítico a un tiempo pasado, proponen restablecer los fundamentos ontológicos históricamente negados para dirimir con ellos los desacuerdos políticos. Al identificar la aparición de la mentira y el alambre como quiebres en el curso de la historia mapuche, los participantes de este taller están expresando mucho más de lo que una escucha rápida podría considerar apresuradamente como obvio. Repensar el territorio desde esos quiebres puede ser un modo de articular el objetivo de revertir las condiciones de desigualdad con el de restaurar ciertas continuidades con el pasado a modo de alternativas políticas. 


\section{Q Referencias Bibliográficas}

» BASSO, Keith. 1988. "Speaking with Names: Language and Landscape among the Western Apache”. Cultural Anthropology, 3 (2): 99-130.

" BENJAMIN, Walter. 2001. Tesis de Filosofía de la Historia. Barcelona: Etcétera, Correspondencias de la Guerra Social.

» BRIONES, Claudia y DELRIO, Walter. 2002. "Patria sí, colonias también. Estrategias diferenciadas de radicación de indígenas en Pampa y Patagonia". En: Fronteras, ciudades y estados. Córdoba: Alción. pp. 45-78.

" CAÑUMIL, Pablo y RAMOS, Ana. 2016. "Algunas reflexiones sobre los procesos de formación de lof”. En: Briones, C. y Kradolfer, S. (Eds.) Dinámicas políticas e identarias de pueblos indígenas: pertenencias, límites y fronteras, Berlin: Estudios Indiana de la editorial Gebr. Mann Verlag (en prensa).

" CAÑUQUEO, Lorena. 2004. "El Territorio Mapuche desde la perspectiva del Ngutram". Asuntos Indígenas, Derechos territoriales. International Work Group for Indigenous Affairs (IWGIA), 4 (4): 33-37.

" CAÑUQUEO, Lorena. 2015. “Tramitando comunidad indígena en Río Negro. Diálogos entre activismo, políticas de reconocimiento y co-gestión”. Revista Identidades, 8: 61-8o.

" CAÑUQUEO, Lorena y TOZZINI, Alma. 2013. “Ideas de territorio en disputa. Un análisis desde la implementación de la Ley № 26.160 en Río Negro". stas. Jornadas de Historia de la Patagonia, Comodoro Rivadavia, 15 al 17 de abril.

» COURSE, Magnus. 2012. "The birth of the word". Hau. Journal of Ethnography Theory, 2 (1): 1-26.

》 CRESSWELL, Tim 2004. Place: A Short Introduction. Oxford: Blackwell

»DE LA CADENA, Marisol. 2015. Earth beings: ecologies of practice across Andean worlds. Durham/Londres: Duke University Press.

》DELRIO, Walter. 2005. Memorias de expropiación. Sometimiento e incorporación indígena en la Patagonia (1872-1943). Bernal: Universidad Nacional de Quilmes.

» DI GIMINIANI, Piergiorgio. 2015. "The Becoming of Ancestral Land: Place and Property in Mapuche Land Claims". American Ethnologist 42 (3): 40-503

» FOLEY, John Miles. 1995. The singer of tales in performance. Bloomington e Indianápolis: Indiana University Press.

» GOLLUSCIO, Lucía. 2006. El pueblo mapuche: poéticas de pertenencia y devenir. Buenos Aires: Biblos.

" GOLLUSCIO, Lucía y RAMOS, Ana. 2007. “El 'hablar bien' mapuche en zona de contacto: valor, función poética e interacción social”. Signo y Seña, Revista del Instituto de Lingüística, 17: 93-114.

» GONZÁLEZ GALVÁN, Marcelo. 2015. "The truth of experience and its communication: Reflections on Mapuche epistemology". Anthropological Theory, 15 (2): 141-157.

» GUIÑAZÚ, Samanta y COHEN, Sebastián. 2012. “Construyendo territorialidades. Nuevas y viejas formas de pensar, sentir y habitar el territorio". Mimeo.

"INGOLD, Tim. 2011. Essays on movement, knowledge and description. Nueva York: Routledge. 
》 KOHN, Eduardo. 2002. "Infidels, Virgins and the Black-Robed Priest: A Back Woods History of Ecuador's Montaña Region”. Ethnohistory, 49 (3): 545-82.

"KRADOLFER, Sabine. 2001. "La importancia del don como fundamento para las relaciones sociales en las comunidades mapuche de Argentina". Scripta Ethnológica, XXIII: 133-143.

» MARIMAN QUEMENADO, Pablo. 2014. Trai Traiko Mapu Ñi Tukulpazugun. Memoria e historia mapuche de los territorios de Imperial. Región de la Araucanía: Municipalidad de Nueva Imperial, Consejo Nacional de la Cultura y las Artes.

" MASSEY, Doreen. 2005. For Space. Londres: Sage.

"NADASDY, Paul. 2002. “'Property' and Aboriginal Land Claims in the Canadian Subarctic: Some Theoretical Considerations". American Anthropologist, 104 (1): 247-261.

" PÉREZ, Pilar. 2016. Archivos del silencio. Estado, indígenas y violencia en Patagonia Central 1878-1941. Buenos Aires: Prometeo.

» RAMOS, Ana. 2005. "Narrativas de origen y sentidos de pertenencia”. RUNA, 25: 131-143.

»RAMOS, Ana. 2010. Los pliegues del linaje. Memorias y políticas mapuches-tehuelches en contextos de desplazamiento. Buenos Aires: Eudeba.

"RAMOS, Ana. 2016. “La memoria como objeto de reflexión: recortando una definición en movimiento". En: A. Ramos, C. Crespo y A. Tozzini (Eds.). Memorias en lucha. Recuerdos y silencios en contextos de subordinación y alteridad. San Carlos de Bariloche: Universidad Nacional de Río Negro. pp. 51-70.

»RAMOS, Ana. 2017. "Cuando la memoria es un proyecto de restauración: el potencial relacional y oposicional de conectar experiencias”. En: A. Bello, Y. González, P. Rubilar y O. Ruiz (Eds.). Historias y memorias. Diálogos desde una perspectiva interdisciplinaria. Temuco: Núcleo de Ciencias Sociales y Humanidades de la Universidad de La Frontera. pp. 32-50.

"RAMOS, Ana y KRADOLFER, Sabine. 2011. "Las memorias de ruta. Repensando los movimientos y las fijezas". Anuario Americanista Europeo, 9: 101-118.

" RAPPAPORT, Joanne. 2005 [1994]. Cumbe Renaciente. Una historia etnográfica andina. Bogotá: Instituto Colombiano de Antropología e Historia (ICANH) y Universidad del Cauca.

»STRATHERN, Marilyn. 2004. "The Whole Person and Its Artifacts". Annual Review of Anthropology, 33: 1-19.

» VOLOSHINOV, Valentín N. 1992 [1929]. El marxismo y la filosofía del lenguaje. Madrid: Alianza.

"WOLIN, Richard. 1994. Walter Benjamin: An Aesthetic of Redemption. Berkeley: University of California Press. 